\title{
Observation of Scintillation Events from GPS and NavIC (IRNSS) Measurements at Bangalore Region
}

\author{
Manjula T R ${ }^{1}$, Raju Garudachar ${ }^{2}$ \\ Department of Electronics and communication \\ SET, Jain University, \\ Bangalore -562112, India
}

\begin{abstract}
Ionosphere scintillation is a random phenomenon of the ionosphere, causing abrupt fluctuations in the amplitude and phase of the signals traversing the medium, significantly impacting the performance of navigation systems, signifying the need to take up scintillation studies. Scintillation events are monitored on L5, S and L1 band signals of IRNSS and GPS navigation system respectively over low latitude Bangalore region during moderate and low solar activity period, 2015 and 2016 respectively. Investigations into scintillation variability with respect to local time, solar activity and seasonal variations are conducted to draw a trend of scintillation pattern. Comparison of L5 and L1 band scintillation events demonstrate similar scintillation pattern with varying scintillation magnitude. With $S$ band signals exhibit minimum scintillation, suggesting the scintillation-free link for effective navigation.
\end{abstract}

Keywords-Ionosphere scintillation; Navigation; carrier to noise ratio; solar activity; equinox

\section{INTRODUCTION}

The ionosphere extending from 50 to $1000 \mathrm{~km}$ from the Earth's surface is formed of ionized particles. The RF signal transmission from satellite, traversing through the ionosphere as shown in Fig.1 undergoes refraction and diffraction. The refraction changes the velocity and direction of an EM wave, introducing delay in the received signal [1]. The diffraction causes mutual interference of the Electromagnetic waves, giving rise to random fluctuations in the amplitude and phase of the radio signal [2] referred to as ionosphere scintillation. The velocity of propagation of radio wave in the ionosphere is determined by density of electrons which is measured in Total electron count (TEC) units, 1TEC unit is equal to $10^{16}$ electrons $/ \mathrm{m}^{2}$. The TEC is defined as the number of electrons measured along a vertical shaft of area $1 \mathrm{~m}^{2}$ connecting satellite and receiver. The TEC is mathematically computed as $\int_{p} N d s . \mathrm{N}$ is the electron density, $\mathrm{p}$ is the propagation path. TEC is be computed $\frac{1}{40.3}\left[\frac{f_{1}^{2} f_{2}^{2}}{f_{1}^{2}-f_{2}^{2}}\right]\left(p_{2}-p_{1}\right)$.where $\mathrm{p} 1$ and p2 are group path lengths and f1 and f2 are high and low frequency signals respectively.Ionosphere scintillation is a random phenomena exhibiting high level of variability with respect to seasons months and solar activity.

The scintillation activity extends upto $\pm 30^{\circ} \mathrm{N}$ and $\mathrm{S}$ of geomagnetic equator and severe scintillation is observed in auroral zones and in the regions close to equator in the belt of $\pm 10^{\circ}$ of equator. Moderate levels of scintillation are monitored in low latitude regions and low or rare events over mid latitude regions. Several studies have reported scintillation occurrence as a night-time phenomenon occurring between local sunset and midnight and rarely extends until postmidnight hours. Scintillation events tend to increase with increase in solar activity as solar radiation intensifies the ionization process and greatly increasing the electron density in the ionosphere.

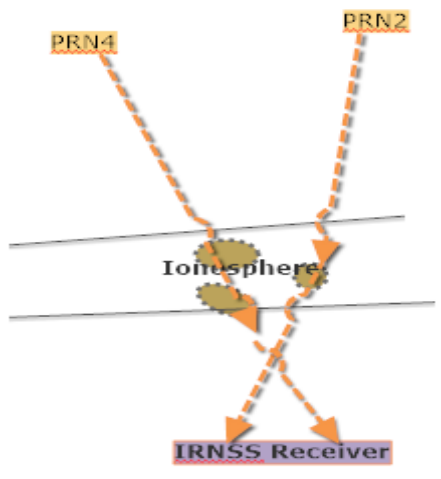

Fig. 1. Pictorial representation of Ionosphere scintillation

The objective of this article is to provide statistical analysis of scintillation occurrence over Bangalore zone. Drawing a pattern of scintillation variability with respect to months, seasons and solar activity. Investigating the Vulnerability of satellites links to scintillation and lastly the comparison of scintillation occurrence on L5, S and L1 band.

Section 2 describes the methodology adopted to carry out this study with some samples of C/No plots. Section 3 presents statistical analysis of scintillation occurrence with respect to various parameters (local time, months, seasons, solar activity)

\section{A. The Cause of Scintillation}

The background electron density of the ionosphere undergoes severe variation from low solar activity to high solar activity period and from equator to anomaly crest sites. Further due to plasma instability processes during the post sunset period in the equatorial region, triggers several nighttime phenomena such as equatorial spread F (ESF) [3] which are prominent factors controlling the occurrence of ionosphere scintillation. Several experimental research and studies are 
carried out to draw pattern of scintillation activity in the stations close to and away from equator to characterize variability in scintillation activity.

\section{B. Impact of scintillation on navigation systems}

Ionosphere scintillation significantly impacts the performance of navigation systems: GPS and IRNSS. Amplitude and phase scintillation of the signal causes signal fading which is witnessed as fluctuations of carrier to noise ratio in the order 15 to $20 \mathrm{~dB} . \mathrm{Hz}$. The signal goes undetected if the signal fading exceeds fade margin of the receiver, thereby increasing signal acquisition time. Further signal distortion, data loss, cycle slips [4], loss of lock on the signal are some of the degrading effects of scintillation on the receiver performance. This study is further extended to investigate the adaptability level of the system to scintillation environment [5].

\section{Related work}

The detailed study on various aspects of scintillation has been carried out in various locations of India particularly in Equatorial Ionization anomaly (EIA) crest regions $\left[20-25^{0}\right.$ geo magnetic latitude]: Calcutta [6], Delhi [7], Varanasi [8] and Ahmadabad [9] as these sites are the origins of precursors of onset of scintillation activity. Scintillations events are monitored in Udaipur region on $244 / 250 \mathrm{MHz}$ radio beacon signals [10] exhibit nighttime characteristics associated with equatorial spread F (ESF) phenomenon. Spatial and temporal variability pattern of scintillation occurrence is monitored and recorded from $240 \mathrm{MHz}$ geostationary satellite signals [11].The scintillation Studies has also been conducted in the regions close to the equator in Ascension Island [12], Africa and India. All these studies attempted to draw a definite pattern of scintillation variability relative to solar activity, seasonal fluctuations and other factors. In all these studies reported, scintillation is a nighttime phenomenon and occurs in discrete patches of irregular interval. It is significant to monitor scintillation activity pattern and its variability over Bangalore region, to estimate scintillation activity pattern and confirm the findings with similar work carried out at various regions of India and other countries

\section{DATA ANALYSIS}

Scintillation occurrence is monitored on IRNSS navigational signals from geostationary IRNSS satellites (1A, $1 \mathrm{~B}, 1 \mathrm{C}, 1 \mathrm{D}, 1 \mathrm{E}, 1 \mathrm{~F}, 1 \mathrm{G})$ at $\mathrm{L} 5$ and $\mathrm{S}$ band signals over Bangalore region -JGI campus, Jain University, kanakapura $\left(\mathbf{1 2 . 6 4 3}^{\circ} \mathbf{N}, \mathbf{7 7 . 0 0 4 4}^{\circ} \mathbf{E}\right)$ from 2015 to 2016 time period using IRNSS receiver which continuously tracks IRNSS/GPS signals. The carrier to noise ratio $(\mathrm{C} / \mathrm{No})$ of the received signal is investigated for the occurrence of scintillation.

The seasonal variation of scintillation is monitored by grouping month wise data into 3 seasons, viz equinoxes (March, April, September \& October), winter months (January, February, November and December) and summer months (May, June, July, August). To assess the influence of solar activity on occurrence of scintillation, scintillation analysis is carried out for the year 2015 as this year experiences moderate solar activity (100-140 solar flux units )and the year 2016, experiences low solar activity (80100 solar flux units).

It is observed that during day time, the nominal variation of $\mathrm{C} / \mathrm{No}$ is $5 \mathrm{~dB} . \mathrm{Hz}$ while rapid and abrupt fluctuations in the order on $8-20 \mathrm{~dB} \mathrm{~Hz}$ are observed during night hours, is one of the characteristics of scintillation. Some typical records of $\mathrm{C} / \mathrm{N} 0$ recorded at Bangalore is shown in the Fig.2. As is apparent, scintillation is primarily a night-time phenomenon, identified as rapid fluctuations of $\mathrm{C} / \mathrm{No}$ in the order $8-20 \mathrm{dBHz}$ against nominal variation of $5 \mathrm{dBHz}$.

\section{RESULTS AND DISCUSSION}

From Fig.2, it is observed that scintillation being a night time activity starts 3 to $4 \mathrm{hrs}$ of local sunset time $6.30 \mathrm{pm}$ and reaches peak values any time between 22 to $22.30 \mathrm{hrs}$ and persists for short duration in post-midnight and declines in activity towards dawn. It is also observed that the Scintillation occurs in discrete patches of irregular intervals in pre and postmidnight hours as reported in $[10,11]$. $\mathrm{S}$ band signals observe nominal variation of $5 \mathrm{dBHz}$ in $\mathrm{C} / \mathrm{No}$ as shown in the Fig. 3.

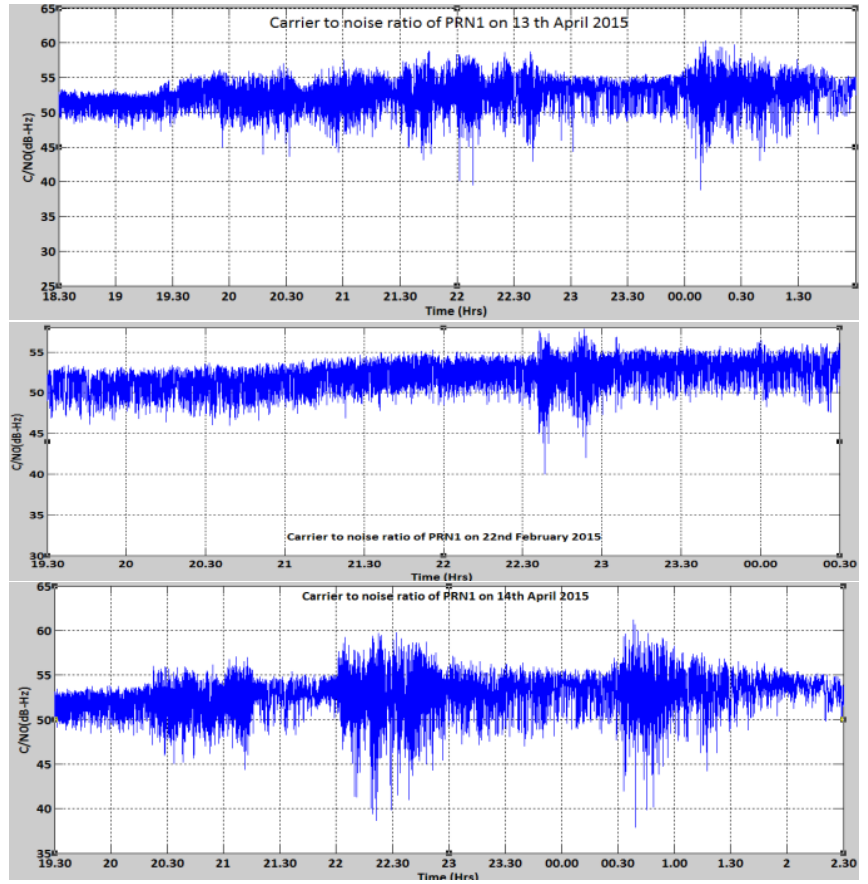

Fig. 2. Carrier to noise ratio of the signal at L5 band from geostationary IRNSS satellite recorded at Bangalore

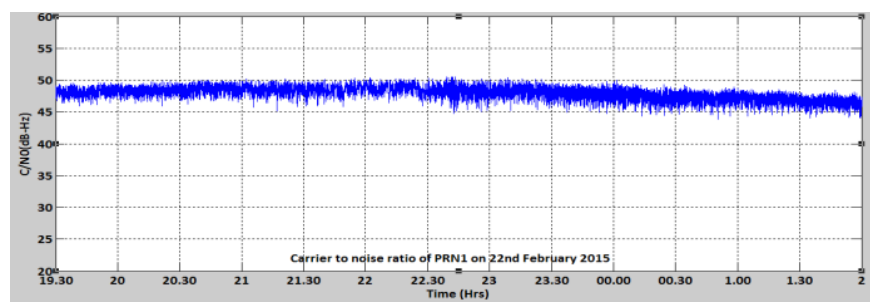

Fig. 3. Carrier to noise ratio of the signal at $\mathrm{S}$ band from geostationary IRNSS satellite recorded at Bangalore

Fig. 4 illustrates month wise, percentage of scintillation for the year 2015 and 2016, characterized as moderate and low 
solar activity period respectively. Highest percentage of scintillation is witnessed during moderate solar activity period (2015) and highest percentage recorded in the April month $(63 \%)$ followed by March $(45 \%)$. The percentage of scintillation has declined to $16 \%$ in low solar activity period which is recorded in the April and March month of the year 2016. May, June, November and December month has not witnessed any scintillation irrespective of the solar activity. From Fig. 5, scintillation activity observed for equinoxes complements the Fig. 4 and its observations. The observations reported very well agree with findings of [10].

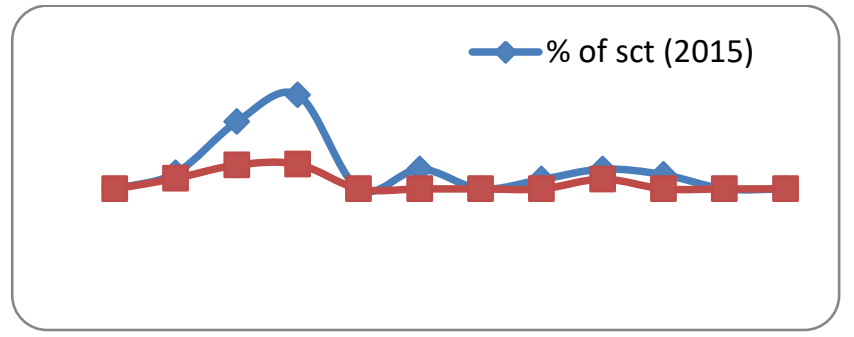

Fig. 4. Percentage occurrence of scintillation for moderate and low solar activity period (2015-2016)

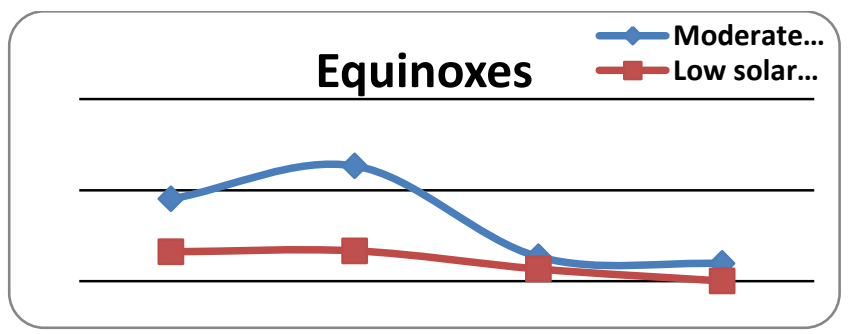

Fig. 5. Percentage scintillation for equinoxes of moderate and low solar activity period (2015\& 2016)

Percentage scintillation witnessed for equinox months in moderate and low solar activity is illustrated in Fig. 6, it is evident that the scintillation activity started at local sunset and gradually increased in intensity and attained peak values (20-25\%) at around 21.30-22.30 Hrs, after attaining peak values, the percentage scintillation decreased from midnight to post midnight. The percentage of scintillation has decreased to $5-7 \%$ during low solar activity period.

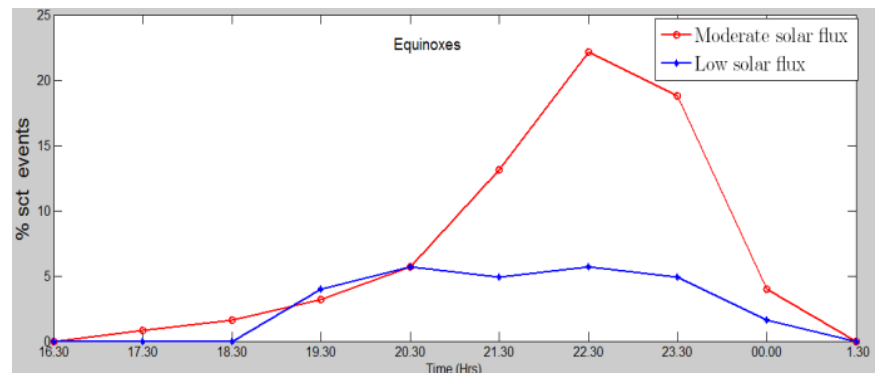

Fig. 6. Nocturnal variation of percentage of scintillation over Bangalore region in equinoxes of the moderate and low solar activity period (2015-2016)

The highest percentage (20-25\%) of scintillation occurrence is observed in equinoxes, less in winter $(2.5 \%)$ and least in summer $(2.2 \%)$ in moderate solar activity period. Peak occurrence of scintillation activity is between 22:00 and 23:00 hrs as apparent from Fig.7. During low solar activity period, the percentage of scintillation has declined to (5-6\%) in equinoxes and $1-2 \%$ in winter and summer months witnessing zero scintillation events. Thus solar activity has direct influence on the scintillation activity as the year 2015 witnesses high percentage of scintillation events than the year 2016. However irrespective of solar activity, equinoxes witnesses high scintillation events compared to winter and summer seasons.

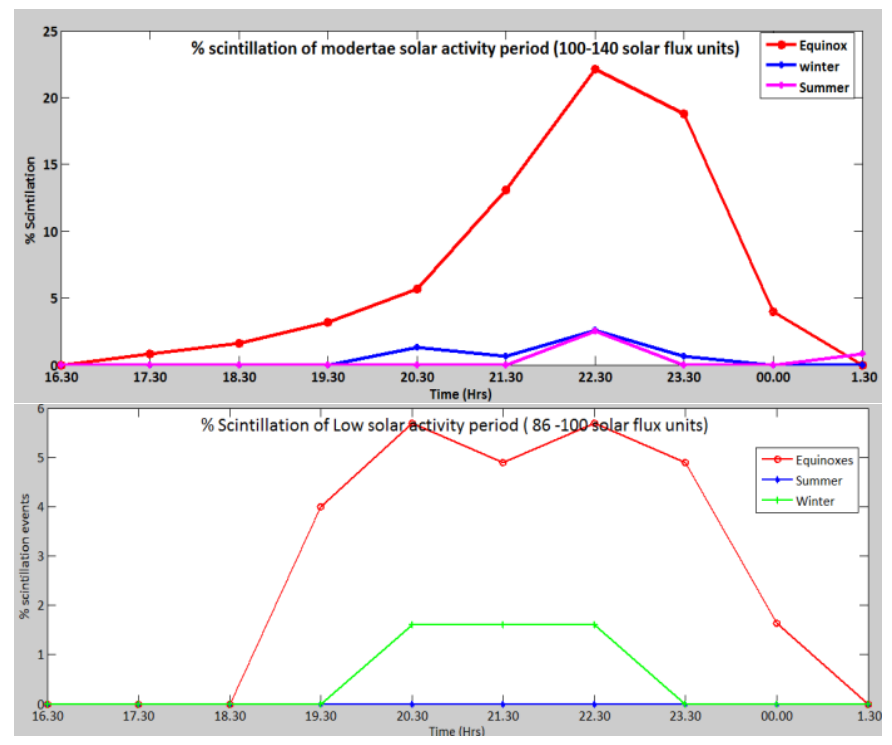

Fig. 7. Percentage of scintillation for seasons during moderate and low solar activity period (2015-2016)

The satellites of IRNSS constellation of the period 2015, prone to scintillation in equinox months with varying level of percentage scintillation experienced with respect to time as illustrated in the Fig.8. The satellites are experiencing varying level of scintillation in night hours and go hand in hand with scintillation activity. However all satellite links are not simultaneously prone to scintillation except at around 22:00 23:00 hrs, satellites PRN1 to PRN4 experiences high percentage $(25-35 \%)$ of scintillation in equinox months $(17.30-20.30)$

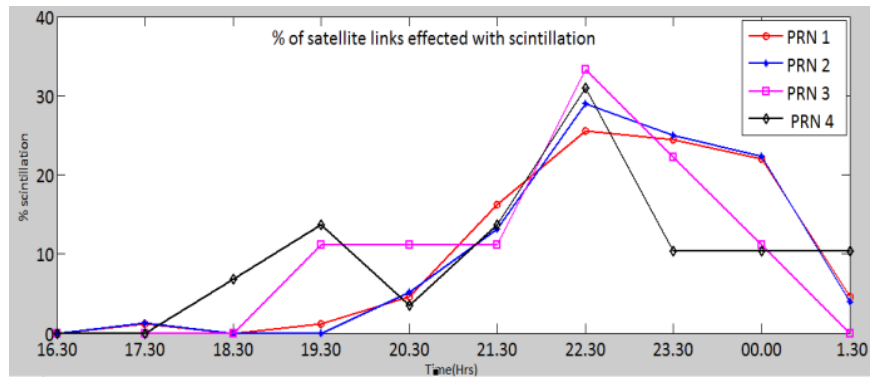

Fig. 8. Percentage of IRNSS satellites links vulnerable to scintillation in the post sunset period of moderate solar activity (2015)

$\mathrm{C} / \mathrm{No}$ undergo rapid fluctuations in scintillation phase. The variation in $\mathrm{C} / \mathrm{No}$ is categorized as $8-10,10-15,15-18,18-20$ $\mathrm{dB} \mathrm{Hz}$. The percentage variation in $\mathrm{C} / \mathrm{No}$ with respect to night time hrs is illustrated in the Fig. 9. Mild variation in C/No (8$12 \mathrm{~dB})$ in low percentages $(<10 \%)$ is observed in pre midnight hrs ) while large variation in C/No $(15-20 \mathrm{~dB})$ is observed in 
$40-50 \%$ at around $22.30-23.30 \mathrm{Hrs}$. Hence variations in $\mathrm{C} / \mathrm{No}$ are direct influence of scintillation activity.

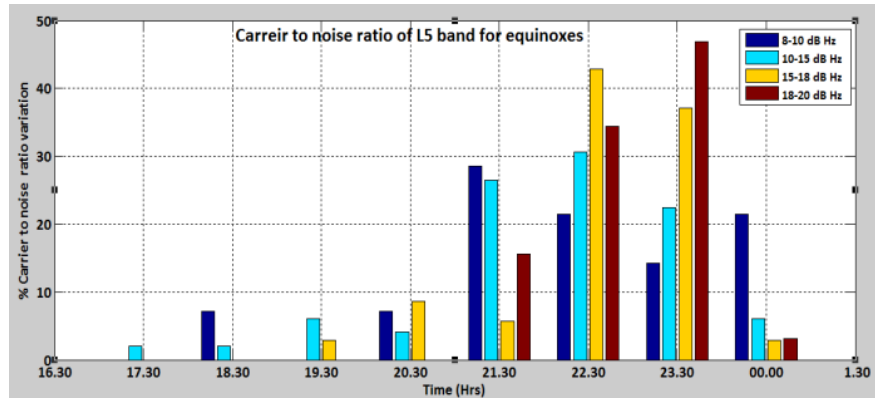

Fig. 9. Percentage variation in carrier to noise ratio for equinox months of moderate solar activity period (2016)

Duration of scintillation occurrence is monitored for April month of moderate solar activity period (2016).It is observed that scintillation occurrence in time duration ranges from 3-50 minutes. As investigated, scintillation occurrence is sometimes continuous for time duration of 30-45 minutes while also exhibiting discrete patchy nature of occurrence for time duration ranging from 5, 20 to 30 minutes. Further scintillation occurrence in varying time duration is observed during both pre and post-midnight hrs.

\section{OBSERVATION AND COMPARISON OF SCINTILLATION OCCURRENCE ON IRNSS (L5 AND S ) AND GPS (L1) BANDS}

Irregular, patchy and rapid fluctuations of $\mathrm{C} / \mathrm{No}$ is observed in the order $15-20 \mathrm{~dB} \mathrm{~Hz}$ on L5 band signals while similar pattern fluctuations in the order $10-15 \mathrm{~dB} \mathrm{~Hz}$ observed on L1 band signals and 6-8 dB variations on $\mathrm{S}$ band signals as illustrated in the Fig.10 implying the low frequency signals are more prone to scintillation than high frequency signals.

High percentage (1.6-22.2\%) of nocturnal scintillation is observed on L5 band signals followed by L1 $(0.8-11.5 \%)$ and least percentage $(1.6 \%)$ on $\mathrm{S}$ band signals during equinox months of moderate solar activity period. The trend of scintillation being minimum in the post sunset hours increases gradually and attain peak maximum in the pre-midnight hours and gradually decreases in post-midnight to zero as observed for both L5 and L1 band and pattern differing for $\mathrm{S}$ band as shown in the Fig.11.

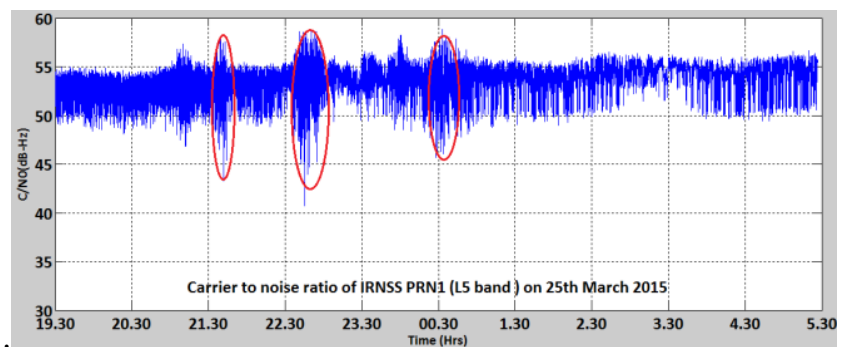

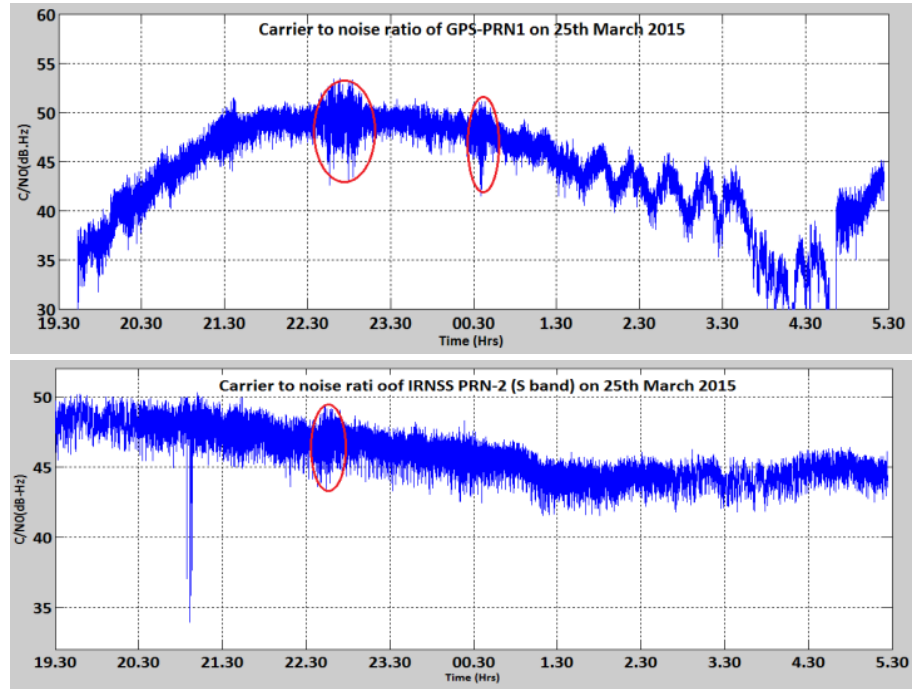

Fig. 10. Plot of Carrier to noise ratio of $\mathrm{L} 5, \mathrm{~L} 1$ and $\mathrm{S}$ band signals

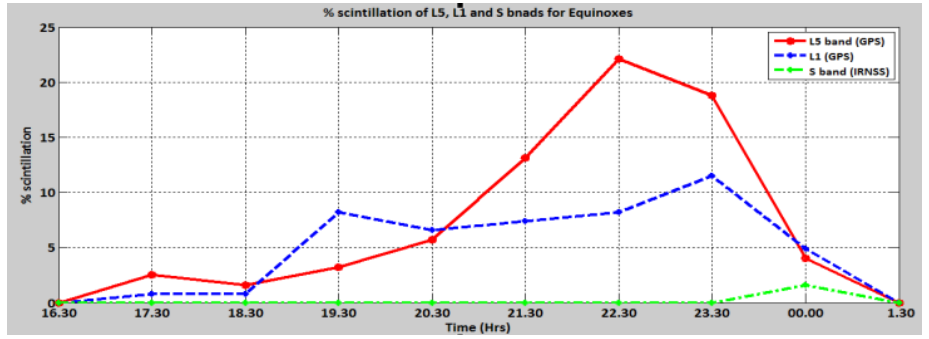

Fig. 11. Comparison of percentage of scintillation of L5, L1 and S band during equinoxes

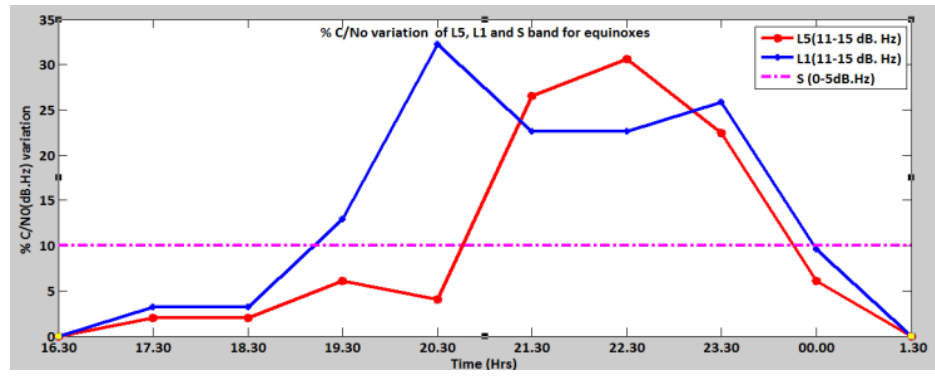

Fig. 12. Percentage of nocturnal $\mathrm{C} / \mathrm{No}$ variation in the range $11-15 \mathrm{~dB} \mathrm{~Hz}$ of $\mathrm{L} 5, \mathrm{~L} 1$ and $\mathrm{S}$ band

The percentage variation of $\mathrm{C} / \mathrm{No}$, more or less follows similar pattern for both L5 and L1 band signals except peak percentage is observed at different timings in the pre-midnight hours. The variation attains maximum percentage of $32.2 \%$ at around 20.30 and $30.6 \%$ at around 22.30 for L1 and L5 signals respectively while $\mathrm{S}$ band signals experiences a constant $0-5$ $\mathrm{dB} \mathrm{Hz}$ variation in $\mathrm{C} / \mathrm{No}$. The summary of above observations are tabulated in Table. 1 
TABLE. I. COMPARISON OF \% OF SCINTILLATION OCCURRENCE FOR EQUINOX MONTHS

\begin{tabular}{|c|c|c|c|}
\hline \multirow{2}{*}{$\begin{array}{l}\text { Solar } \\
\text { activity } \\
\text { (solar flux } \\
\text { units) }\end{array}$} & \multirow[b]{2}{*}{$\begin{array}{l}\text { Frequency } \\
\text { bands }\end{array}$} & \multicolumn{2}{|c|}{ Equinox months } \\
\hline & & $\begin{array}{l}\% \text { of } \\
\text { Scintillation }\end{array}$ & $\begin{array}{l}\mathrm{C} / \mathrm{No} \\
\text { variation } \\
(\mathrm{dB} \mathrm{Hz})\end{array}$ \\
\hline \multirow{3}{*}{$\begin{array}{l}\text { Moderate } \\
(100-140)\end{array}$} & $L 5$ & $20-25$ & $15-20$ \\
\hline & L1 & $0.8-11.5$ & $10-15$ \\
\hline & $S$ & $<1.6$ & $6-8$ \\
\hline \multirow{3}{*}{$\begin{array}{l}\text { Low } \\
(80-100)\end{array}$} & L5 & $5-6$ & $1-5$ \\
\hline & L1 & $<1$ & $1-5$ \\
\hline & $S$ & 0 & $1-5$ \\
\hline
\end{tabular}

\section{CONCLUSION}

In this paper, observed characteristics of night time scintillation on L5 band signals over low latitude Bangalore region has been discussed in terms of month to month, seasonal and solar cycle variation. During moderate solar activity period, scintillation occurrence is more frequent with highest percentage recorded in equinoxes. The percentage occurrence of scintillation decreases with solar activity and scintillation recorded in low solar activity period is $1-5 \%$ in equinoxes, less and least events are recorded in winter and summer months respectively. Irrespective of solar activity, equinox months witnesses the scintillation events with percentage occurrence comparatively higher than that witnessed during low solar activity period. The scintillation events start at or after 3 to $4 \mathrm{hrs}$ of local sunset time depending on the solar activity level and attain maximum peaks around (22:00- 23:30) Hrs. Post-midnight scintillations are also observed in equinoxes in discrete patches. Random variation of $\mathrm{C} / \mathrm{No}$ in the order of $8-20 \mathrm{~dB}$ is observed during night scintillation hours as compared to nominal variation of $5 \mathrm{~dB} . \mathrm{Hz}$ during day time. About $25-35 \%$ of scintillation at L5 band is experienced by all satellites of IRNSS constellation in the moderate solar activity period (2015) during equinoxes around 22:00-23:00 hrs while an $\mathrm{S}$ band IRNSS signal experiences zero or less scintillation. Comparison of L5 and L1 band scintillation shows that though L1 experiences low percentage of scintillation follows similar pattern of scintillation activity as that of L5 band signals as also expected.

Next phase of the work: consequent to the observations of the scintillation events, the work will be extended to study the impact of scintillation on GNSS Receiver performance and also address the scintillation mitigation techniques.

\section{ACKNOWLEDGEMENT}

The authors would like to thank ISRO for facilitating SET, Jain University with IRNSS receiver. The project was carried out at IRNSS laboratory of Electronics and communication department of Jain University. I am thankful to Jain University for giving an opportunity to execute and publish the paper

\section{REFERENCES}

[1] Soumi Bhattacharya, P.K Purohit, A. K Gwal," Ionospheric time delay variations in equator anomaly region during low solar activity using GPS", Indian Journal of Radio \& Space physics,pp.266-274,2009.

[2] P. M Kinter, B. M Ledvina. "GPS and Ionospheric scintillations", Space Weather, 5, Sep 2007.

[3] J Hanumath Sastri," Patchy occurrence of equatorial spread F", Annals Geophysicae, pp.589-592, 1985.

[4] Todd E. Humphreys, Mark L Psiaki, Paul M," Modelling the effects of ionospheric scintillation on GPS carrier phase tracking", IEEE transactions on aerospace and electronic systems, pp.1624-1637, 2010.

[5] Manjula T R, G Raju, " Comphrensive study of Linear Kalman filter Based Tracking techniques under Ionosphere scintillations", RAEREST 2016, Kerala, March 2016

[6] Das Gupta A, Maitra A \& BASU, "Occurrence of night time VHF scintillations near the equator anomaly crest in the Indian sector", Radio science, 16, PP. 1455,1981

[7] Dabas R S, Lakshmi D R \& Reddy B M., “ Effect of geomagnetic disturbances on the VHF night time scintillations activity at equatorial and low latitudes", Radio science, 24, PP. 563, 1989

[8] R P Patel, A.K. Singh, R P Singh, "Study of the ionospheric irregularities by GPS measurements at low latitude station, Varanasi", Proceedings of Beacon Satellite Symposium, June 2010

[9] Vyas G D \& Chandra H, "VHF scintillations and spread $F$ in the anomaly crest region", Indian Journal of Radio and space physics, pp. 157, 1994.

[10] B M Vyas, B Dyananda, "Nighttime VHF ionospheric scintillation characteristics near the crest of Appleton anomaly station, Udaipur (26.40 N, 73.70 E)", Indian Journal of Radio and space physics,pp.191202, 2011.

[11] S Chatterjee, S.K Chakraborthy, "Variability of ionospheric scintillation near the equator anomaly crest of the Indian zone", Ann. Geophysics., pp. 697-711, 2013.

[12] K. M. Groves, S. Basu, J. M. Quinn, T. R. Pederse, K. Falinski , “ A comparison of GPS performance in a scintillation environmemnt at Ascension Island", proceedings of ION GSP 2000,

[13] K.C.T Swamy, A. D Sarma, A Supraja Reddy, “ Analysis of Ionosphere scintillation of GPS and VHF/UHF signals over low latitude Indian region", Information and communication Technologies (WICT), 2012 World Congress, IEEE, 2012. 